\title{
A STUDY ON E- SECURITY ISSUES AND COUNTERMEASURES
}

\author{
Shama Parveen \\ Amity University, Chhattisgarh \\ Mohammad Bakhtawar Ahmad \\ Amity University, Chhattisgarh
}

\section{Abstract:}

The quick advancement of figuring and correspondence advances and their standardization have made the blast in internet business conceivable. Bringing down of the cost of task, increment in the speed of exchanges, and simple worldwide reach to clients and merchants have been the purposes behind the mind-boggling ubiquity of this better approach for business. In any case, there is as yet a huge part of customers whose security fears affect how they spend their cash on the web. Along these lines, security issues related with online business and client locales must be continually looked into and refreshed with fitting countermeasures. The motivation behind this paper is to clarify the significance of E-trade security and will talk about Pretty Good Privacy, public key infrastructure, digital signatures and other cryptography procedures in E-business security.

Keywords: MITM, SSL, PGP, PKI, CA

\section{INTRODUCTION}

The fast development of E- Business is pulling in the consideration of organizations with its qualities high-proficiency, minimal effort, high-productivity and worldwide application. Internet business is a critical piece of which the e-business idea is made of. Internet business speaks to another method for making business utilizing the offices offered by the advances that are rising every single day available. A firm can utilize online business to achieve limit showcase sections that are generally scattered topographically. E-commerce companies in India are Flipkart, Amazon India, Paytm etc[3].

Online business furnishes purchasers with a more extensive scope of decisions than customary commerce, because they can think about a wide range of items and administrations from a more extensive assortment of venders. The advantages of internet business likewise reach out to the general welfare of society. Electronic installments of assessment discounts, open retirement, and welfare bolster cost less to issue and arrive safely and immediately when transmitted by means of the Internet. Moreover, electronic installments can be less demanding to review and screen than installments made with check, which can help ensure against extortion and burglary misfortunes. internet business can make items and administrations accessible in remote territories. For instance, remote training is making it workable for individuals to learn abilities also, acquire degrees regardless of where they live or what hours of the day they have accessibility for consider. Not only it is easier than ever to collect the data, but also much easier to search these data[6].

Notwithstanding innovation issues, numerous organizations confront social and lawful obstacles to web based business. A few shoppers are still to some degree dreadful of sending their charge 
card numbers over the Internet. The legitimate condition in which web based business is led is loaded with vague and clashing laws. As a rule, government controllers have not stayed aware of advances. As more organizations and people discover the advantages of internet business convincing, a significant number of these innovation and culture-related detriments will vanish.

Another essential issue is security. Exchanges amongst purchasers and merchants in online business incorporate solicitations for data, citation of costs, position of requests and installment, and after deals administrations. The high level of certainty required in the genuineness, privacy, and auspicious conveyance of such exchanges can be hard to keep up where they are traded over the Internet. The capture attempt of exchanges, and specifically charge card subtle elements, amid transmission over the Internet is frequently a noteworthy obstruction to open trust in online business.

Strategies for interfacing all the product and equipment components in simply the correct method to help electronic trade are changing and developing regular. The rate of progress is fast for all components that help electronic business. Any business that takes part in web based business and wants to contend later on must adjust to new web advancements as they wind up accessible. The expected web based business over-burden expects organizations to discover quicker and more proficient approaches to manage the regularly expanding surge of online customers and the expanding activity between organizations.

\section{E-SECURITY ISSUES}

\section{A. Client-side Security Issues}

From the client's perspective, customer side security is regularly the significant concern. As a rule, customer side security requires the utilization of conventional PC security advances, for example, legitimate client confirmation and approval, get to control, and hostile to infection assurance. Concerning correspondence benefits, the customer may moreover require server confirmation and non-revocation of receipt. Furthermore, a few applications may require secrecy such as unknown perusing on the Web. Most banks utilize single figure security setting framework is powerless against infection and digital assaults. One of the critical normal for web based keeping money is that it can offer sheltered and customized client benefit whenever, anyplace and at any rate. Without sound security insurance will cause web based saving money exchange fall flat.

Most basic attacks, for example, spying, mitm and so on can be .In a spying assault, an inactive or dynamic system attacker tunes in on other clients' system activity, for example, DNS questions, HTTP asks for and responses,etc. By spying on their system movement, an attacker isn't just ready to learn delicate, individual data, for example, charge card information, budgetary means, usernames, passwords, substance of email messages, and so forth., yet can likewise tune in on vital Web metadata, for example, session identifiers or as far as anyone knows mystery treats.

In a man-in-the-middle attack (MitM), a dynamic system attacker positions himself in the system, between the casualty and the focused on Web application. This position not just enables the attacker to assess all movement that is sent between the casualty and the objective application, yet in addition permits alteration of the activity. 


\section{B. Server-side Security Issues}

Server-side security is commonly the real worry from the specialist organization's perspective. Server-side security requires legitimate customer validation and approval, non-disavowal of origin, sender secrecy (e.g., mysterious distributing on the Web), review trail and responsibility, and additionally unwavering quality and accessibility.

\section{Network Security Issues}

Packet sniffers are bits of programming that screen organize activity. At the point when information exchanges from the customer's PC to the internet business site, it needs to go through numerous associations. Thus, the information can be perused by any PC it goes through and an aggressor can sniff the system effortlessly and take individual data, for example, Visa numbers and passwords.

\section{Database threats}

Online business frameworks store client information and recover item data from databases associated with the web-server. Other than item data, databases associated with the web contain important and private data that could hopelessly harm an organization on the off chance that it were revealed or modified. A few databases store username/watchword matches in a non-secure manner. On the off chance that somebody gets client confirmation data, at that point he or she can take on the appearance of a honest to goodness database client and uncover private and exorbitant data

III. RECENT ATTACKS

\begin{tabular}{|c|c|c|}
\hline Year & Attack Name & Nature of Attack \\
\hline 2018 & Ransomy & $\begin{array}{l}\text { Adams Health Network, which runs Adams Memorial } \\
\text { Hospital, has affirmed that a ransomware assault focused on } \\
\text { some of its PC servers [10] }\end{array}$ \\
\hline 2018 & $\begin{array}{l}\text { Porsche Japan } \\
\text { customers data breach }\end{array}$ & $\begin{array}{l}\text { Porsche says in excess of } 28,000 \text { email addresses have been } \\
\text { spilled through a hack[10] }\end{array}$ \\
\hline 2017 & Equifax & $\begin{array}{l}\text { Intruders infiltrated Equifax (EFX), one of the biggest credit } \\
\text { authorities, in July and stole the individual information of } 145 \\
\text { million people[8] }\end{array}$ \\
\hline 2017 & WannaCry & $\begin{array}{l}\text { WannaCry, which spread over in excess of } 150 \text { nations, } \\
\text { utilized a portion of the spilled NSA instruments. In May, the } \\
\text { ransomware focused on organizations running obsolete } \\
\text { Windows programming and secured PC frameworks.[8] }\end{array}$ \\
\hline 2017 & NotPetya & The malware spread to major worldwide organizations [8] \\
\hline 2016 & Indian Debit Card Hack & $\begin{array}{l}\text { Upwards of } 32 \text { lakh charge cards having a place with different } \\
\text { Indian banks were compromised[11] }\end{array}$ \\
\hline 2016 & Dyn DDos Attack & $\begin{array}{l}\text { cybercriminals propelled major DDoS assaults, disturbing a } \\
\text { large group of sites [9] }\end{array}$ \\
\hline 2016 & Yahoo Data Breach & $\begin{array}{l}500 \text { million clients may have had information stolen, } \\
\text { including delicate subtle elements, for example, names, email } \\
\text { addresses, telephone numbers and hashed passwords [9] }\end{array}$ \\
\hline
\end{tabular}




\section{A. Digital Signatures \& Certificates}

\section{E-SECURITY SOLUTIONS}

A digital signature is a numerical strategy used to approve the credibility and respectability of a message, programming or advanced report. Advanced marks give the necessity to verification and integrity[2].

Digital Certificate is issued by a trusted outsider which demonstrates sender's character to the collector and beneficiary's personality to the sender. Computerized mark is utilized to confirm legitimacy, respectability, non-revocation ,i.e. it is guaranteeing that the message is sent by the known client and not altered, while advanced declaration is utilized to check the character of the client, possibly sender or beneficiary. Along these lines, computerized mark and authentication are distinctive sort of things yet both are utilized for security. Most sites utilize advanced endorsement to upgrade trust of their clients.

\section{B. Secure Socket layer}

Secure Sockets Layer (SSL) is a standard security innovation for setting up an encoded interface between a server and a customer - commonly a web server (site) and a program, or a mail server and a mail customer.

SSL permits touchy data, for example, Visa numbers, government disability numbers, and login accreditations to be transmitted safely. Typically, information sent amongst programs and web servers is sent in plain content-abandoning you helpless against spying. In the event that an assailant can capture all information being sent between a program and a web server, they can see and utilize that data.

All the more particularly, SSL is a security convention. Conventions depict how calculations ought to be utilized. For this situation, the SSL convention decides factors of the encryption for both the connection and the information being transmitted. Exchange security relies upon the association's capacity to guarantee protection, genuineness, honesty, accessibility and the obstructing of undesirable interruptions [5]. All programs have the ability to collaborate with secured web servers utilizing the SSL convention. Be that as it may, the program and the server require what is called a SSL Certificate to have the capacity to build up a protected association. SSL secures a huge number of people groups' information on the Internet consistently, particularly amid online exchanges or when transmitting secret data. Web clients have come to connect their online security with the bolt symbol that accompanies a SSL-secured site or green address bar that accompanies an Extended Validation SSL-secured site. SSL-secured sites additionally start with https instead of http. This is the most broadly perceived security strategy, open key encryption; it ensures mystery, affirmation, information uprightness, and non disavowal of commencement and return [7]

\section{Public Key Infrastructure}

A PKI permits clients of the Internet and other open systems to participate in secure correspondence, information trade and cash trade. This is done through open and private cryptographic key sets gave by an endorsement expert. PKI regularly requires an incorporated, exceptionally accessible mediator for key administration, and particularly for incite warning about denied key-pairs[4]

A PKI is an establishment on which different applications and system security segments can fabricate. Frameworks that frequently require PKI based security instruments incorporate E-mail, 
different chip card applications, esteem trade with E-business, home saving money, and electronic postal frameworks. A declaration specialist (CA) is the substance giving the keys. The private key will be given to the individual asking for the key. People in general key is made open in an index for clients. Nobody can ever discover what somebody's private key is, failing to be accessible on the Internet. The private key is utilized for demonstrating client character and encoding the advanced authentication. The computerized authentication will be unscrambled by people in general key, which is utilized by the message recipient.

There are a few organizations empowering a PKI. The enrollment procedure for an advanced authentication starts with an enlistment expert (RA). This registration must happen before the CA knows regardless of whether the client will be issued an endorsement. There are numerous pieces engaged with PKI. Legitimately empowered, these give smooth, straightforward and secure interchanges.

\section{Pretty Good Privacy}

PGP is a procedure utilized for scrambling and decoding computerized documents and correspondences over the Internet. PGP chips away at the general population key cryptography system, where clients scramble and decode information utilizing their individual open and private keys. PGP utilizes a symmetric encryption key to encode messages, and an open key is utilized with each sent and got message. Initially, the beneficiary must utilize its private key to decode the key and after that unscramble the message through the decoded symmetric key.

PGP likewise gives information/document trustworthiness benefits by carefully marking messages, enabling collectors to learn regardless of whether message classification is traded off. PGP is particularly utilized for E-mail security which can give Authentication and Confidentiality[1].

PGP is additionally used to scramble documents put away on a PC or potentially total hard circle drives.

\section{CONCLUSION}

A great deal of research on E- Business security is going on and numerous security items and frameworks of online business are being produced and advertised. In this circumstance, take note of that security is a framework property of the web based business. Not exclusively should web based business locales and shoppers judge security vulnerabilities and survey potential specialized arrangements, they should likewise evaluate, assess, and resolve the dangers included. Security, trustworthiness, privacy and non disavowal are primary security measurement to ensure E-business exchanges against dangers. In this research paper diverse methodologies has been introduced that expands the level of security measurements utilizing cryptographic strategies.

\section{REFERENCES}

I. Kuldeep Kaur, Dr. Ashutosh Pathak, Parminder Kaur, Karamjeet Kaur, "E-Commerce Privacy and Security System", International Journal of Engineering Research and Applications, ISSN : 2248-9622, Vol. 5, Issue 5,( Part-6) May,2015. 
II. Shazia Yasin, Khalid Haseeb, Rashid Jalal Qureshi, "Cryptography Based E-Commerce Security: A Review", International Journal of Computer Science Issues, Vol. 9, Issue 2, No 1, March 2012.

III. Palak Gupta, Dr. Akshat Dubey, "E-Commerce-Study of Privacy, Trust and Security from Consumer's Perspective", IJCSMC, Vol. 5, Issue. 6, June 2016.

IV. Rankl, W., and W. Effing. 1997. The Smartcard Handbook.New York: John Wiley.

V. Ravi Kalakota, Andrew B. Whinston. "Electronic Commerce: A Manager's Guide", Addison-Wesley, ISBN: 0-201-88067-9.

VI. Winner, D. 2002. "Making Your Network Safe for Databases", SANS Information Security Reading Room, July 21, 2002.

VII. A.Sanayei and Rajabion, Lila. E-Commerce and Security Governance in Developing . Isfahan, Iran., 2008.

VIII. http://money.cnn.com/2017/12/18/technology/biggest-cyberattacks-of-theyear/index.html

IX. https://www.forbes.com/forbes/welcome/?toURL=https://www.forbes.com/sites/kevinandert on/2017/03/29/8-major-cyber-attacks-of-2016-

infographic/\&refURL=https://www.google.co.in/\&referrer=https://www.google.co.in/

X. https://www.databreaches.net

XI. https://economictimes.indiatimes.com/industry/banking/finance/banking/3-2-million-debitcards-compromised-sbi-hdfc-bank-icici-yes-bank-and-axis-worsthit/articleshow/54945561.cms 